\title{
The effect of gender on $\mathrm{EC}_{50}$ of remifentanil to prevent pain during injection of microemulsion propofol
}

\author{
Bo-Won Lee ${ }^{1}$, Sang-Hun $\mathrm{Kim}^{1,2}$, and Keum-Young So ${ }^{1,2}$ \\ Department of Anesthesiology and Pain Medicine, ${ }^{1}$ Chosun University Hospital, ${ }^{2}$ Chosun University School of Medicine, Gwangju, \\ Korea
}

Background: Propofol injection pain is an unpleasant experience to patients and its prevalence can be influenced by age and gender. We determined the half maximal effective concentration $\left(\mathrm{EC}_{50}\right)$ of remifentanil for preventing the microemulsion propofol injection pain in the male and female adult groups.

Methods: After institutional review board approval, a total of 60 patients were assigned into 2 groups depending on their gender: group M (male, 20-65 yr) and group F (female, 20-65 yr). Anesthesia was induced with propofol and remifentanil, by a target-controlled infusion. Target effect-site concentration (Ce) of propofol and remifentanil for the first patient started at $4.0 \mathrm{ug} / \mathrm{ml}$ and $4.0 \mathrm{ng} / \mathrm{ml}$. Ce of remifentanil for each subsequent patient was determined by the response of the previous patient by the Dixon's up-and-down method (DUDM) with an interval of $0.2 \mathrm{ng} / \mathrm{ml}$. After equilibration of plasma and effect site remifentanil concentration, propofol was administered, and the pain responses were observed.

Results: The remifentanil $\mathrm{EC}_{50}$ was $3.8 \pm 0.2$ and $2.7 \pm 0.2 \mathrm{ng} / \mathrm{ml}$ in groups $\mathrm{M}$ and F, respectively, by DUDM. From Probit regression model, the remifentanil $\mathrm{EC}_{50}$ was $3.7(3.0-4.3)$ and $2.7(1.8-2.9) \mathrm{ng} / \mathrm{ml}$ in groups $\mathrm{M}$ and $\mathrm{F}$, respectively.

Conclusions: The remifentanil $\mathrm{EC}_{50}$ for preventing the moderate to severe injection pain of propofol was higher in males than in females. (Korean J Anesthesiol 2012; 63: 504-509)

Key Words: Gender identity, Pain, Propofol, Remifentanil.

Received: March 9, 2012. Revised: 1st, April 8, 2012; 2nd, May 13, 2012; 3rd, June 20, 2012; 4th, July 9, 2012. Accepted: July $10,2012$. Corresponding author: Keum-Young So, M.D., Ph.D., Department of Anesthesiology and Pain Medicine, Chosun University School of Medicine, 588, Seasuk-dong, Dong-gu, Gwangju 501-717, Korea. Tel: 82-62-220-3223, Fax: 82-62-223-2333, E-mail: kyso@chosun.ac.kr

(c) This is an open-access article distributed under the terms of the Creative Commons Attribution Non-Commercial License (http:// creativecommons.org/licenses/by-nc/3.0/), which permits unrestricted non-commercial use, distribution, and reproduction in any medium, provided the original work is properly cited. 


\section{Introduction}

Target-controlled infusion (TCI) is a useful technique for total intravenous anesthesia (TIVA). Propofol and remifentanil have similar characteristics, such as the rapid onset time and a short clinical duration, and thus, they are suitable for TIVA applying TCI. Nonetheless, propofol injection pain has been of interest to anesthesiologists to the level that it is the 7 th of 33 clinical problems pertinent to anesthesia [1]. Microemulsion propofol (Aquafol ${ }^{\circledR}$, Daewon Pharmaceutical Co., Ltd, Seoul, South Korea), which has been developed recently and used, has advantages of minimizing complications associated with lipid emulsion propofol. Nevertheless, it has been shown that microemulsion propofol induces more frequent and more severe injection pain than lipid emulsion propofol [2]. Recently, numerous studies have been conducted to reduce or prevent propofol injection pain. Opioid pretreatment has been used widely as one of the methods [3-6]. Most investigators administered opioid by bolus injection. However, recently, it has been reported that propofol injection pain could be reduced more efficiently when an effective concentration of remifentanil is maintained by the application of TCI [7]. In addition, it has been reported that propofol injection pain may be influenced by gender; female patients were more sensitive to propofol injection pain [8].

The purpose of this study was to investigate the effect of gender on half maximal target effect-site concentration $\left(\mathrm{EC}_{50}\right)$ of remifentanil by the application of TCI that prevents the moderate to severe injection pain of microemulsion propofol.

\section{Materials and Methods}

Institutional Review Board approved this study and informed consent was obtained from all patients. Sixty patients, aged 20 years or older, who were American Society of Anesthesiologists physical status I or II, were enrolled. Patients with allergy to anesthetic medications, poor venous access, neurologic deficit, and psychiatric disorder were excluded.

Patients were allocated to one of two groups, according to gender: the male group (group $\mathrm{M}, 20-65 \mathrm{yr}, \mathrm{n}=30$ ) and the female group (group F, 20-65 yr, $\mathrm{n}=30$ ). All patients were not premedicated with any medication for hypnosis and sedation before anesthesia. An $18 \mathrm{G}$ venous cannula was kept at the largest vessel on the dorsum of the hand and lactated Ringer's solution was infused. When patients arrived at the operating room, standard monitoring was applied and a $22 \mathrm{G}$ arterial catheter was inserted in the radial artery, under local anesthesia, after a modified Allen's test for continuous blood pressure monitoring. All patients were preoxygenated for $5 \mathrm{~min}$ using a facemask before the anesthetic induction.
Patients received TIVA with remifentanil and microemulsion propofol. Remifentail infusion was based on a Minto pharmacokinetic model, using a TCI device (Orchestra ${ }^{\circledR}$ Base Primea, Fresenius-Vial, France) [9]. The target effect-site concentration (Ce) of remifentanil was $4.0 \mathrm{ng} / \mathrm{ml}$ for the first patient [7]. Thirty seconds after equilibration of plasma and effect site remifentanil concentration was reached, TCI of propofol was then started at a target plasma concentration $4.0 \mu \mathrm{g} / \mathrm{ml}$ using the integrated Marsh model [10,11]. Pain from propofol infusion was assessed using the four-point verbal categorical scoring system before the loss of patient's consciousness [12]: 0, none (negative response to questioning); 1, mild pain (pain reported only in response to questioning without any behavioral signs); 2 , moderate pain (pain reported in response to questioning and accompanied by a behavioral sign or pain reported spontaneously without questioning); 3, severe pain (strong vocal response or response accompanied by facial grimacing, arm withdrawal or tears). If they had a score of 2 or 3, this scored as 'response'; if they had a score of 0 or 1 , it was regarded as 'no response.' Thereafter, Ce of remifentanil for subsequent patient was increased or decreased, as the patient's response by using Dixon's up-and-down method [13,14]. If a patient had 'response', Ce of remifentanil for subsequent patient was increased by $0.2 \mathrm{ng} / \mathrm{ml}$. If a patient had 'no response, Ce of remifentanil for the subsequent patient was decreased by $0.2 \mathrm{ng} / \mathrm{ml}$ [14].

The $\mathrm{EC}_{50}$ of remifentanil was determined by using the Dixon up-and-down method, which calculates the mean of midpoint dose of all independent pairs of patients who manifested a crossover from "response" to "no response" after eight crossover points. Probit analysis was used to calculate a dose response curve and confidence intervals and estimated $\mathrm{EC}_{50}$ and $\mathrm{EC}_{95}$ were calculated.

Patient's heart rate (HR) and the mean arterial pressure (MAP) were recorded before remifentanil infusion and microemulsion propofol infusion. We assessed the remifentanil related complications, such as hypotension (decrease in MAP by more than 20\%), bradycardia (HR slower than 45 beats/min), chest tightness (if patients complain of a chest tightness or difficulty in breathing), oxygen desaturation $\left(\mathrm{SpO}_{2}\right.$ below $\left.90 \%\right)$, dizziness, nausea and pruritus. If the MAP dropped below $50 \mathrm{mmHg}$, ephedrine $0.25 \mathrm{mg} / \mathrm{kg}$ was scheduled, and if the bradycardia occurred, atropine $0.5 \mathrm{mg}$ was scheduled.

SPSS (Windows ver. 19.0, SPSS Inc., Chicago, IL) was used for statistical analysis. Probit regression model and Sigma Plot 9.0 was used for calculating the confidence interval and plotting the dose response curve. All measured values were denoted as the mean \pm SD, number of patients and mean (95\% confidence intervals, CI). The mean arterial pressure and heart rate were analyzed by the Mann-Whitney $U$ test to make comparison between groups $\mathrm{M}$ and $\mathrm{F}$, at individual time points. $\mathrm{EC}_{50}$, 
calculated by the Dixon's up-and-down method, were analyzed by the Mann-Whitney $\mathrm{U}$ test to compare group $\mathrm{M}$ with F. $\mathrm{P}$ values $<0.05$ were considered statistically significant.

\section{Results}

Table 1 presents the patients' demographic data. The numbers of assigned patients in group $\mathrm{M}$ and $\mathrm{F}$ were 28 and 24, respectively.

The mean arterial pressure and heart rate exhibited a significant decrease in groups $\mathrm{M}$ and $\mathrm{F}$ after equilibration between plasma and effect-site remifentanil concentrations

Table 1. Demographics Data

\begin{tabular}{lcc}
\hline & Group M $(\mathrm{n}=28)$ & Group F $(\mathrm{n}=24)$ \\
\hline Gender (M/F) & $28 / 0$ & $0 / 24$ \\
Age (yr) & $38.9 \pm 12.6$ & $42.9 \pm 14.7$ \\
Height $(\mathrm{cm})$ & $171.8 \pm 4.6$ & $159.6 \pm 5.3$ \\
Weight $(\mathrm{kg})$ & $67.9 \pm 10.1$ & $57.5 \pm 9.3$ \\
\hline
\end{tabular}

Values are mean \pm SD or number of patients. Group M (male, 20-65 yrs) and group F (female, 20-65 yrs). was reached $(\mathrm{P}<0.05)$, but there were no significant differences between groups $\mathrm{M}$ and $\mathrm{F}$ (Table 2).

$\mathrm{EC}_{50}$ of remifentanil for preventing microemulsion propofol injection pain calculated using the Dixon's up-and-down method was $3.8 \pm 0.2$ and $2.7 \pm 0.2 \mathrm{ng} / \mathrm{ml}$ in groups $\mathrm{M}$ and $\mathrm{F}$, respectively (Table 3, Fig. 1). It was significantly higher in group $\mathrm{M}$, compared with group $\mathrm{F}(\mathrm{P}=0.001)$.

The predictive $\mathrm{EC}_{50}$ of remifentanil calculated, using the Probit regression model, were 3.7 (95\% confidence interval (CI), $3.0-4.3)$ and 2.7 (95\% CI, 1.8-2.9) $\mathrm{ng} / \mathrm{ml}$ in groups $\mathrm{M}$ and $\mathrm{F}$,

Table 3. Effect-site Concentrations of Remifentanil

\begin{tabular}{lcc}
\hline & $\begin{array}{c}\text { Group M } \\
(\mathrm{n}=28)\end{array}$ & $\begin{array}{c}\text { Group F } \\
(\mathrm{n}=24)\end{array}$ \\
\hline $\begin{array}{l}\mathrm{EC}_{50} \text { by Dixon's up-and-down } \\
\text { method (ng/ml) }\end{array}$ & $3.8 \pm 0.2$ & $2.7 \pm 0.2^{*}$ \\
$\mathrm{EC}_{50}$ by probit regression $(\mathrm{ng} / \mathrm{ml})$ & $3.7(3.0-4.3)$ & $2.7(1.8-2.9)$ \\
$\mathrm{EC}_{95}$ by probit regression $(\mathrm{ng} / \mathrm{ml})$ & $4.5(4.0-16.3)$ & $3.1(2.9-7.4)$
\end{tabular}

Values are mean \pm SD and mean (95\% confidence interval). Group $\mathrm{M}$ (male, 20-65 yrs) and group F (female, 20-65 yrs). *P $<0.05$ compared with Group M.

Table 2. Changes in Mean Arterial Pressure and Heart Rate after Remifentanil Infusion

\begin{tabular}{llcc}
\hline & & Group M (n=28) & Group F (n=24) \\
\hline MAP (mmHg) & Baseline & $95.6 \pm 10.8$ & $93.2 \pm 9.0$ \\
HR (beats/min) & Post-remifentanil & $89.1 \pm 14.5^{*}$ & $87.0 \pm 12.7^{*}$ \\
& Baseline & $70.0 \pm 15.0$ & $71.1 \pm 11.1$ \\
& Post-remifentanil & $65.4 \pm 16.0^{*}$ & $64.7 \pm 8.9^{*}$ \\
\hline
\end{tabular}

Values are mean \pm SD. Group M (male, 20-65 yrs) and group F (female, 20-65 yrs). MAP: mean arterial pressure, HR: heart rate, Baseline: before administration of remifentanil, Post-remifentanil: immediately after equilibration of plasma and effect site concentration of remifentanil. $* \mathrm{P}<0.05$ compared with baseline within each group.
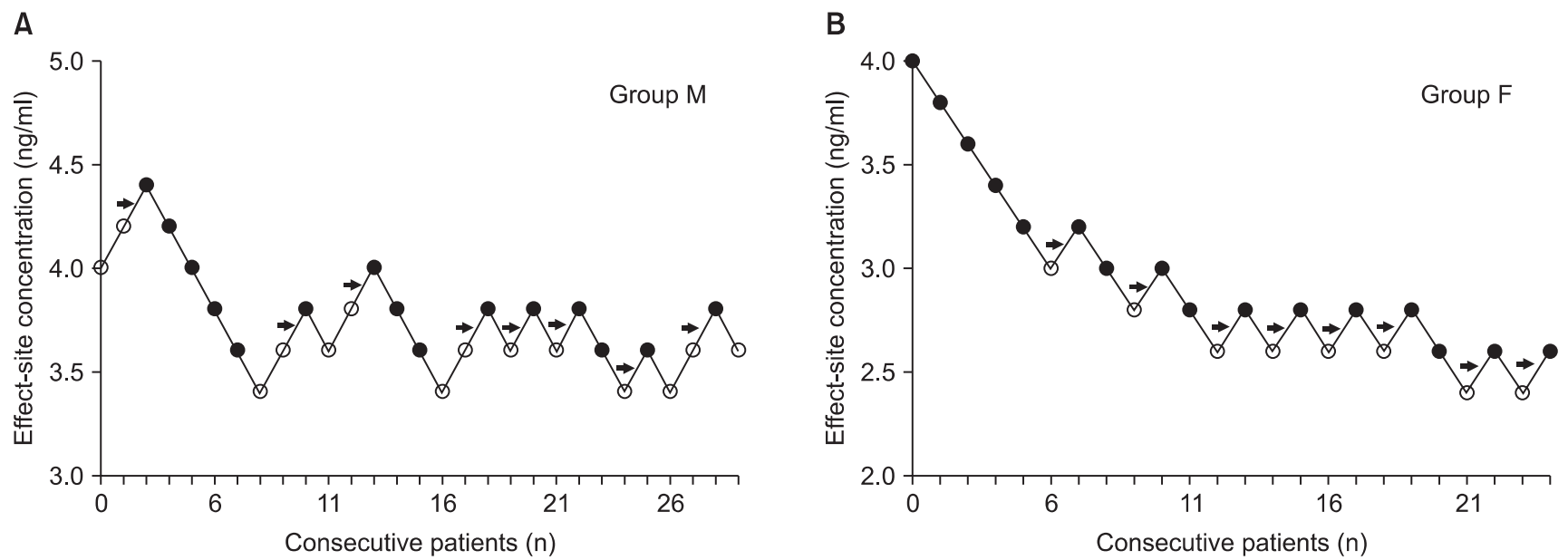

Fig. 1. Consecutive target remifentanil concentrations for determining the $\mathrm{EC}_{50}$. The arrow represents the mean remifentanil concentration when crossing from significant pain (white circles) to no pain (black circles). The average of these concentrations is the $\mathrm{EC}_{50} . \mathrm{EC}_{50}$ is $3.8 \pm 0.2$ and $2.7 \pm 0.2 \mathrm{ng} / \mathrm{ml}$ in the group M (A) and F (B). Group M (male, 20-65 yrs) and group F (female, 20-65 yrs). 


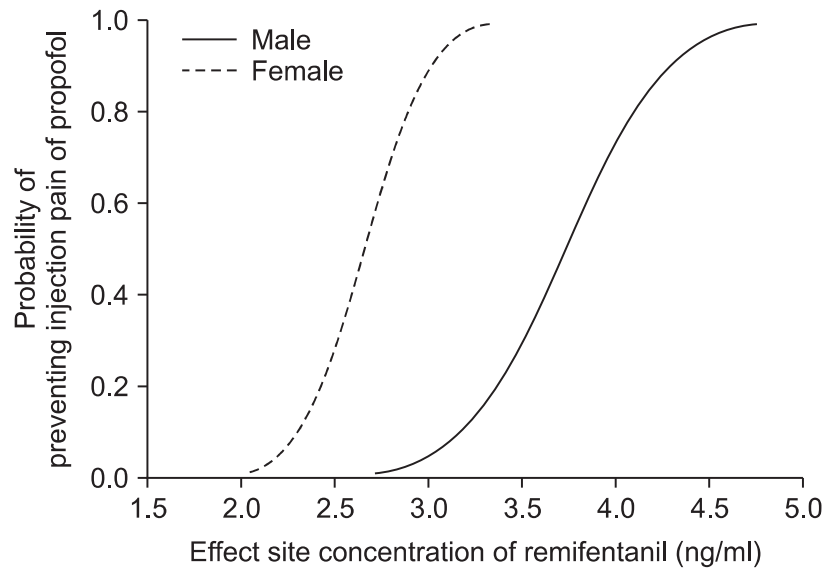

Fig. 2. Dose response curves plotted from probit analysis of individual remifentanil concentration and respective reaction to propofol injection. $\mathrm{EC}_{50}$ is 3.7 (95\% CI, 3.0-4.3) and 2.7 (95\% CI, 1.8-2.9) in the group $\mathrm{M}$ and $\mathrm{F}$. $\mathrm{EC}_{95}$ is 4.5 (95\% CI, $\left.4.0-16.3\right)$ and 3.1 (95\% CI, $2.9-7.4) \mathrm{ng} / \mathrm{ml}(95 \% \mathrm{CI}, 3.6-4.5)$ in the group $\mathrm{M}$ and F. Group $\mathrm{M}$ (male, 20-65 yr) and group F (female, 20-65 yr).

respectively (Table 3, Fig. 2). In addition, the predictive EC95 of remifentanil were 4.5 (95\% CI, 4.0-16.3) and 3.1 (95\% CI, 2.9$7.4 \mathrm{ng} / \mathrm{ml}$ (95\% CI, 3.6-4.5) in group M and F, respectively (Table 3, Fig. 2).

\section{Discussion}

The purpose of this study was to assess the half maximal effective concentration $\left(\mathrm{EC}_{50}\right)$ of remifentanil that could prevent microemulsion propofol injection pain, according to gender. Remifentanil $\mathrm{EC}_{50}$ that prevents microemulsion propofol injection pain in male and female was $3.7-3.8 \mathrm{ng} / \mathrm{ml}$ and 2.7 $\mathrm{ng} / \mathrm{ml}$, respectively.

Several studies on the difference of the sensitivity to opioids, such as remifentanil, according to gender, as well as $\mathrm{EC}_{50}$ reported diverse results. At first we hypothesized that remifentanil has similar effects to prevent injection pain of microemulsion propofol to rocuronium, according to gender, because the mechanism of injection pain of microemulsion propofol is similar to that of rocuronium. Both drugs activate the kallikreinkinin system in plasma, and release local mediators, such as bradykinin; thus, irritate the nociceptor of vein $[15,16]$. In this study, remifentanil $\mathrm{EC}_{50}$ for the prevention of microemulsion propofol injection pain in males was higher than in females, which was an inverse result from the study reported by Park et al. [17], One of the suspected reasons showing the differences is the difference in the spaced test level and the line of demarcation between the 'response' and 'no response'. We used $0.2 \mathrm{ng} / \mathrm{ml}$ of the spaced test level, compared with Park's test level, and they excluded the wrist movement. On the other hand, we included the patient with reported behavioral sign and pain without questioning. In addition, because the prevalence and intensity of pain were higher and more severe than rocuronium, more patients in groups $M$ and $F$ might be enrolled as the 'response' in our study. Another suspected reason was the difference in opioid requirement for the pain in males and females. Despite the report by Minto et al. [9], which have reported that gender does not exert influence on the pharmacodynamic and pharmacokinetic of remifentanil, according to the studies that examined morphine dosages required for pain control after surgery, it has been reported that males required $40 \%$ higher doses than females to obtain comparable pain reduction effects [18]. These results support that females are more sensitive to the effects of remifentanil, compared with males. Studies concerning the gender differences in drug effects are rare [19], but gender sensitivity may affect the different result of this study. Finally, small sample size might be one of the reasons even if it was sufficient for the Dixon's up-and-down method. The character of Dixon's upand-down method relatively requires small sample size and it is considered that individual susceptibility to opioid influence the result. This is the limitation of this study. Therefore, more studies regarding gender differences of remifentanil effect will be needed on the basis of this study's result.

After the injection of microemulsion propofol, the incidence of pain that is higher than moderate has been reported to be $69.7-84 \%[2,20,21]$. The reason of the high incidence of microemulsion propofol injection pain has not been precisely characterized yet. The opioid pretreatment, that is one of the methods which have been claimed to prevent such injection pain, has been reported to reduce the incidence and severity of propofol injection pain with various results $[3,4,7,22]$. It was well known that opioids, such as remifentanil and alfentanil, acts on the central or peripheral opioid receptors. It has been reported when alfentanil was administered after a tourniquet was inflated on the upper arm for $30 \mathrm{~s}$ before induction of anesthesia, for the reduction or prevention of propofol injection pain, satisfactory results could not be obtained, and it was meant that alfentanil did not control injection pain by peripheral actions [23]. In contrast, Roehm et al. [4] have reported that $0.25 \mu \mathrm{g} / \mathrm{kg} / \mathrm{min}$ remifentanil for longer than 1 minute prior to the injection of propofol reduced injection pain from $62 \%$ to $30 \%$. Basaranoglu et al. [3] have reported that the administration of $0.25 \mu \mathrm{g} / \mathrm{kg} /$ min remifentanil 1 minute prior to the injection of propofol reduced the incidence of injection pain to $44 \%$, and it was more effective than remifentanil administered, immediately prior to the injection of propofol (60\%). This implies that not only the dose of remifentanil, but also the injection time interval, is important to obtain the maximal effects of remifentanil for the prevention of injection pain. In addition, it suggests 
that for the prevention of injection pain, the central action of opioid plays more important roles than peripheral actions. Nevertheless, in the continuous injection at a constant rate calculated by a real body weight, it is difficult to prove the time reaching Ce of remifentanil. When remifentanil is injected by continuous injection, blood concentration is increased slowly. Consequently, the Ce of remifentanil is also increased slowly, and thus, ultimately, during the induction of anesthesia, within limited time, it is difficult to reach the optimal Ce. Since the effectiveness of the drug is affected by the effect-site drug concentration [21], it is clinically important to administer the drugs by the application of Ce. However, there are rare studies on the optimal Ce of remifentanil applied TCI for the effective prevention of pain-inducing drugs, such as propofol and rocuronium [7,24]. Lee et al. [7] have reported that $4.0 \mathrm{ng} / \mathrm{ml} \mathrm{Ce}$ of remifentanil reduced propofol injection pain more effectively than $2.0 \mathrm{ng} / \mathrm{ml}$, and significant differences from $6.0 \mathrm{ng} / \mathrm{ml}$ were not shown. In our study, it was assumed that reaching optimal Ce of remifentanil by the application of TCI would prevent propofol injection pain more effectively than bolus injection, and considering that the incidence of microemulsion propofol inducing pain was higher than lipid emulsion propofol, the initial effective Ce of remifentanil was determined as $4.0 \mathrm{ng} / \mathrm{ml}$.

In the assessment of injection pain, we defined mild pain that patients reported as the pain only in response to questioning without any behavioral signs. We thought that mild pain is acceptable to all patients, and moderate to severe pain is the main problem of microemulsion propofol injection pain. As such, we decided that it is the significant injection pain.

Similar to other opioids, remifentanil may also cause hypotension, bradycardia, chest tightening and hypoxemia. Studies which examined remifentanil $\mathrm{EC}_{50}$ that could prevent hemodynamic changes, caused by endotracheal intubation or injection pain, have reported that $2.0-5.0 \mathrm{ng} / \mathrm{ml}$ remifentanil did not induce significant hypotension, bradycardia, chest tightening and hypoxemia $[17,24,25]$. In our study, in all groups, after the administration of remifentanil, significant reduction of the mean arterial pressure and heart rates was shown. Nonetheless, hypotension and bradycardia that required treatments were not developed. In addition, pre-oxygenation for 5 min using a facemask was performed before the infusion of remifentanil, and thus, hypoxia was not developed.

In conclusion, for the prevention of moderate to severe microemulsion propofol injection pain, remifentanil $\mathrm{EC}_{50}$ in males was higher than in females. Nevertheless, the results were obtained by the application of the Dixon's up-and-down method and the probit regression model from a small number of subjects, and thus, it is considered that additional studies by the application of multiple $\mathrm{EC}_{50}$ are required on the effective Ce of remifentanil for the prevention of microemulsion propofol injection pain without significant side effects on a large number of patients.

\section{Acknowledgments}

This study was supported by research funds from Chosun University, 2010.

\section{References}

1. Macario A, Weinger M, Truong P, Lee M. Which clinical anesthesia outcomes are both common and important to avoid? The perspective of a panel of expert anesthesiologists. Anesth Analg 1999; 88: 1085-91.

2. Sim JY, Lee SH, Park DY, Jung JA, Ki KH, Lee DH, et al. Pain on injection with microemulsion propofol. Br J Clin Pharmacol 2009; 67:316-25.

3. Basaranoglu G, Erden V, Delatioglu H, Saitoglu L. Reduction of pain on injection of propofol using meperidine and remifentanil. Eur J Anaesthesiol 2005; 22: 890-2.

4. Roehm KD, Piper SN, Maleck WH, Boldt J. Prevention of propofolinduced injection pain by remifentanil: a placebo-controlled comparison with lidocaine. Anaesthesia 2003; 58: 165-70.

5. Fletcher JE, Seavell CR, Bowen DJ. Pretreatment with alfentanil reduces pain caused by propofol. Br J Anaesth 1994; 72: 342-4.

6. Honarmand A, Safavi M. Prevention of propofol-induced injection pain by sufentanil: a placebo-controlled comparison with remifentanil. Clin Drug Investig 2008; 28: 27-35.

7. Lee JR, Jung CW, Lee YH. Reduction of pain during induction with target-controlled propofol and remifentanil. Br J Anaesth 2007; 99: 876-80.

8. Kang HJ, Kwon MY, Choi BM, Koo MS, Jang YJ, Lee MA. Clinical factors affecting the pain on injection of propofol. Korean J Anesthesiol 2010; 58: 239-43.

9. Minto CF, Schnider TW, Egan TD, Youngs E, Lemmens HJ, Gambus $\mathrm{PL}$, et al. Influence of age and gender on the pharmacokinetics and pharmacodynamics of remifentanil. I. Model development. Anesthesiology 1997; 86: 10-23.

10. Marsh B, White M, Morton N, Kenny GN. Pharmacokinetic model driven infusion of propofol in children. Br J Anaesth 1991; 67: 41-8.

11. Milne SE, Kenny GN, Schraag S. Propofol sparing effect of remifentanil using closed-loop anaesthesia. Br J Anaesth 2003; 90: 623-9.

12. King SY, Davis FM, Wells JE, Murchison DJ, Pryor PJ. Lidocaine for the prevention of pain due to injection of propofol. Anesth Analg 1992; 74: 246-9.

13. Dixon WJ. Efficient analysis of experimental observations. Annu Rev Pharmacol Toxicol 1980; 20: 441-62.

14. Dixon WJ. Staircase bioassay: the up-and-down method. Neurosci Biobehav Rev 1991; 15: 47-50.

15. Dubey PK, Kumar A. Pain on injection of lipid-free propofol and propofol emulsion containing medium-chain triglyceride: a comparative study. Anesth Analg 2005; 101: 1060-2.

16. Zhang Y, Xiang Y, Liu J. Prevention of pain on injection of rocuronium: a comparison of lidocaine with different doses of parecoxib. J Clin Anesth 2012; 24: 456-9.

17. Park SJ, Park HJ, Choi JY, Kang HS, Choi HS. The influence of age 
and gender on remifentanil EC(50) for preventing rocuronium induced withdrawal movements. Korean J Anesthesiol 2010; 58: 244-8.

18. Sarton E, Olofsen E, Romberg R, den Hartigh J, Kest B, Nieuwenhuijs $\mathrm{D}$, et al. Sex differences in morphine analgesia: an experimental study in healthy volunteers. Anesthesiology 2000; 93: 1245-54.

19. Pleym H, Spigset O, Kharasch ED, Dale O. Gender differences in drug effects: implications for anesthesiologists. Acta Anaesthesiol Scand 2003; 47: 241-59.

20. Jung JA, Choi BM, Cho SH, Choe SM, Ghim JL, Lee HM, et al. Effectiveness, safety, and pharmacokinetic and pharmacodynamic characteristics of microemulsion propofol in patients undergoing elective surgery under total intravenous anaesthesia. $\mathrm{Br} \mathrm{J}$ Anaesth 2010; 104: 563-76.

21. Lee HY, Kim SH, So KY. Prevention of microemulsion propofol injection pain: a comparison of a combination of lidocaine and ramosetron with lidocaine or ramosetron alone. Korean J Anesthesiol 2011; 61:30-4.

22. Iyilikci L, Balkan BK, Gokel E, Gunerli A, Ellidokuz H. The effects of alfentanil or remifentanil pretreatment on propofol injection pain. J Clin Anesth 2004; 16: 499-502.

23. Wrench IJ, Girling KJ, Hobbs GJ. Alfentanil-mediated analgesia during propofol injection: no evidence for a peripheral action. Br J Anaesth 1996; 77: 162-4.

24. Yoon JY, Kim HK, Kwon JY, Shin SW, Kim KH, Kim WS, et al. EC(50) of remifentanil to prevent withdrawal movement associated with injection of rocuronium. J Anesth 2010; 24: 182-6.

25. Yon JH, Jo JK, Kwon YS, Park HG, Lee S. Effect-site concentration of remifentanil for blunting hemodynamic responses to tracheal intubation using light wand during target controlled infusion-total intravenous anesthesia. Korean J Anesthesiol 2011; 60: 398-402. 